\title{
Relative Age in Kindergarten: From the Perspective of Teachers
}

\author{
Kelli Dougan \\ Fayetteville Public Schools
}

\author{
Kara Lasater \\ University of Arkansas
}

John Pijanowski

University of Arkansas

\begin{abstract}
Relative age effects are the outcomes that are manifested when older and younger students are compared in an environment such as a classroom. Research has shown that older students have higher student achievement than younger students (Datar, 2006; Lin et al., 2009; Oshima \& Domaleski, 2006; Yesil-Dagli, 2006). This case study grouped students by their birthdays to form kindergarten classes where the average range of ages were within a four month span. Focus groups were used to determine the effects of this practice from the teachers' perspectives. Some teachers thought that grouping kindergarteners by birthday improved teacher-student relationships, allowed for better student instruction and reduced negative student behaviors. However, other teachers felt burdened by groups of the youngest students and lamented not having older students to teach and model for their younger peers. The teachers in this study thought that the youngest students in a cohort were less prepared for school and required more of their time and instruction than the oldest students.
\end{abstract}

Keywords: kindergarten, relative age effects, teacher-student relationship

\section{INTRODUCTION}

Relative age effects occur due to the differences between the older and younger students in a given classroom. Some of these differences are easy to observe such as height, attention span and fine motor skills. The disparities in age begin when students enter kindergarten. Entrance ages are determined by a set cut-off date and are unique to each state. Students in a typical kindergarten class may be up to twelve months apart in age. Older students begin schooling at later points in their development when compared to their younger peers. These differing development stages are most noticeable when children are young and can produce very different outcomes for students. This case study sought to discover what effects grouping kindergarten students into classes by their birth dates might have on the students and on the teachers' perceptions of relative age. These are the research questions that guided this study:

1) What are the teacher perceptions of placing kindergarten students into classes based on their birthday?

2) What are teacher perceptions of relative age in kindergarten? 


\section{Literature Review}

Relative age effects occur when students of differing ages are compared to one another within the same cohort. The current educational practice of grouping students by age creates a system where some students are relatively older or younger than the peers they interact with in the same class. Though the range of ages in kindergarten may not seem large when they are only a few months apart in age, when examined in terms of the proportion of the child's lifetime, some students are $20 \%$ older than other students. This difference in age consequently results in a wide range of academic and social abilities within the same classroom. Several studies have been conducted to determine the effects of relative age in the classroom, as well as whether or not these effects continue as students move through school.

Relative age effects have been examined in various settings, but Barnsley and Thompson (1988) were among the first researchers to study the phenomenon when they discovered that professional hockey players overwhelmingly had birthdays in the first three months of the year. Helsen et al. (2005) found a similar effect in soccer, though the oldest had birthdays in the summer. Both teams of researchers found that athletes with birthdays near but after the cut-off date for each sport made up not only the oldest players in their respective teams, but also comprised larger percentages of elite teams. Barnsley and Thompson (1988) and Helsen et al. (2005) shared a similar belief in that the issue with relative age effects has more to do with the perceptions of coaches and other adults than any intrinsic talent of the players. When children are young, small differences in age, such as 4 to 12 months, may cause a wide range of physical abilities as well as visible differences in height. These physical differences can have an impact on athletic ability when children are very young, which can be misinterpreted by adults as a disparity in talent. The older and more coordinated children are chosen to be on more advanced teams, given more opportunities to play and thereby becoming better players in their respective sports (Barnesley \& Thompson, 1988; Helsen et al., 2005).

Relative age effects also occur in the classroom. Relatively older students show higher achievement scores in reading and math from kindergarten to at least eighth grade (Datar, 2006; Lin et al., 2009; Oshima \& Domaleski, 2006; Yesil-Dagli, 2006). Younger children are more likely to be retained (Wake et al., 2000) or diagnosed with Attention Deficit Hyperactivity Disorder (ADHD; Elder, 2010). If relative age effects are occurring in the classroom in a similar fashion as in the athletic arena, the issue arises from teachers. If teachers are misinterpreting normal developmental levels for academic potential, then older students would receive more leadership opportunities and rigorous academic assignments, which lead to better achievement, just like their athletic counterparts.

Entering kindergarten can be a stressful period in a child's life and a child's adjustment to kindergarten can affect his long term school success (Alexander \& Entwisle, 1988; Raver, 2002). Children who are able to self-regulate their emotions (Alexander \& Entwisle, 1988; Graziano et al., 2007; Ladd et al., 2006) and have better developed social skills have easier and more positive adjustments to attending school for the first time (Ladd et al., 2006; Pagani \& Allard, 2011). Effective transitions allow students to achieve at higher academic levels because less of their time and energy is spent on coping with the demands of school. Executive functioning skills, such as working memory, self-control and the ability to pay attention, also help students successfully adjust to the new demands of kindergarten (Sasser et al., 2015). The presence or absence of effective executive functioning skills can predict achievement in math and reading in subsequent grades (Morgan et al., 2017). Older children are more likely to possess better developed executive functioning and socio-emotional skills, thereby having a better adjustment to kindergarten and more long term school success than their relatively younger peers.

Research also shows that a positive relationship between teacher and child helps students succeed in kindergarten (Zulfiqar et al., 2018) and in some cases can mediate executive functioning problems (Graziano et al., 2016). This relationship depends on the perception that teachers have about students. Teachers often rate students with low executive functioning skills as less competent (Abry et al., 2015) and beliefs such as this may lead to a less positive teacher-student relationship (Zulfiqar et al., 2018). Students who are younger than their peers are more likely to possess fewer executive functioning skills and are at a higher risk for a negative teacher-student relationship when compared to older peers. However, this does not mean that there is anything lacking in the younger children in terms of normal development. They are 
simply younger than the peers they are being compared to in the classroom. Just as when athletic coaches mistook normal developmental differences between older and younger children for talent, teachers are making the same judgments in the classroom.

\section{Methodology}

Kindergarten students in two elementary schools were placed into classes based solely on their birthday. There were three kindergarten classes in each of the schools, so the students were sorted from oldest to youngest and divided into three approximately equal groups. Both schools ended up with the same approximate range of birthdays in the three groups. The oldest group of students had birthdays before October 20 and also included students who had been retained in kindergarten the previous year. The middle group of students had birthdays between October 20 and March 5, while the youngest group of kindergarteners had birthdays after March 5. No other factors were considered in the separation of classes.

The two schools chosen for this study were located in the same school district. The researchers invited these particular schools to participate because the schools were examining ways to increase student achievement, especially in the K-2 grade span. The demographics of each school is included in Table 1.

TABLE 1

DEMOGRAPHICS OF STUDENTS IN SCHOOL A AND SCHOOL B

\begin{tabular}{|l|l|l|}
\hline Demographic & School A & School B \\
\hline Asian & $.3 \%$ & $3 \%$ \\
\hline Native American & $.3 \%$ & $1.4 \%$ \\
\hline Black/African American & $12.2 \%$ & $21 \%$ \\
\hline Hispanic & $9.4 \%$ & $18.2 \%$ \\
\hline Pacific Island & $2.8 \%$ & $3.6 \%$ \\
\hline White & $60 \%$ & $41.4 \%$ \\
\hline Two or More Races & $15 \%$ & $11.3 \%$ \\
\hline
\end{tabular}

The teachers in this study were those teachers who had been assigned to teach kindergarten. There were three kindergarten classes in each school. The average number of years teaching was 8.95 for School A and 11.9 for School B. None of the participants were first year teachers and all of them had taught kindergarten the previous year. One participant at School B during the first focus group session was a long term substitute who was an experienced kindergarten teacher. In that particular class, the regular teacher returned to school during the second semester and participated in the second focus group.

A case study was conducted using focus group discussions to gather the perspectives of the teachers in the project. A semi-structured group interview was conducted with the teachers twice during the school year near the beginning and near the end of the school year and recorded. Recordings were transcribed, coded and triangulated by the researchers. The responses were analyzed to determine codes and general themes that guided the researchers in the analysis.

\section{Results}

Analysis of the transcripts and follow-up notes revealed three themes that described the perceptions of teachers about grouping kindergarten students by birthday and teachers' perceptions of relative age. 
- Theme 1: Grouping kindergarteners by birthday allows teachers to spend more time on executive functioning and kindergarten adjustment when the youngest students are in the same classroom.

- Theme 2: Teachers prefer to have older students in their classroom to help with younger students.

- Theme 3: Teachers perceive the youngest students in class as requiring more time, support and direct teaching.

\section{Time for Extra Support}

Grouping students by their birthdate allowed for the children to be in the same classes as those peers who were more likely to be similar in social and emotional development. The teachers who were assigned the youngest class could spend extra time on skills that the students needed to help them adjust to kindergarten without worrying that older students would get bored. Laurel commented,

I think I was prepared knowing that I had the younger group. I think you go in as a kindergarten teacher thinking, 'Okay, just get through six weeks.' But for me, I had to realize that this may be longer than six weeks and that's okay. We need some of these skills and we don't have them and we have to keep working on them. I mean, you have to do a lot of breaks anyways with kindergarten, but I found that I had to do even more. And my group would get tired easily, and just a little bit more sensitive. They need a lot more hugs, and a little bit more whiny, just because they are younger and so they're developing skills. I mean, we still do a lot of songs, but I think that's a part of kindergarten, but this group, I noticed, they really like my songs.

This similarity of emotional maturity resulted in fewer discipline issues than in previous years. Teachers at both schools reported a dramatically reduced number of behavior issues that would have resulted in a child being sent to an administrator for punishment. Elizabeth said "I feel like we've had less issues as a whole. I feel like because their ages are closer, they seem to be acting similarly in the classroom."

The range of academic differences was also smaller which allowed the teachers to differentiate less. Teachers who were assigned the older students commented that they were able to move at a faster than normal pace through the kindergarten standards. They were able to transition from kindergarten adjustment to academic learning at a faster pace. Audrey said, "I'm having to plan a lot more enrichment type activities. I usually don't start doing that until about January, but from the very beginning I've needed to look at the first and second grade standards and start pulling stuff from them because they've almost mastered the kindergarten skills already. So, that's something I've done a little different this year." However, the pressure was palpable for the teacher of the youngest students to reach the year-end milestones. Joan M. commented,

Again, I kind of feel a little pressure in that my kids still have to get to those standards by the end of the year and I have every intention of them being there. So I don't know that the learning will be that much different except that the social, emotional side will take a little bit longer and be more deliberate. I know that as a district we feel the pressure for the kindergartners to be at a certain place to meet those standards and I know that the principals probably feel that too.

\section{Older Students Provide Extra Support}

Teachers of the youngest group of students lamented the time needed to work on executive functioning skills and procedures at the beginning of the year. Many teachers had depended on the older students in their classrooms to help manage the younger ones. Older students helped younger ones with getting jackets on and off, redirecting behavior, and in many cases, teaching academic skills. Without older students in their classroom, teachers felt more stress with these tasks than in years before. Joan M. stated "In the past, 
I've had one or two that could be the helpers. I have less of that so we're having to kind of learn all of that together."

Teachers in this study may not have used the words "relative age" when referring to students, but they made several comments about the extra time and support that the youngest students need in order to be successful in kindergarten. Joan said,

I have the youngest group. I think we're seeing that it takes a lot longer to overcome some things that typically we get through in the first six weeks of school. So I still see tears on occasion and frustration and there's no one in my class that knows how to tie shoes. I think the outcome expectation is the same for kindergarten that we have to meet the standards, so regardless of age, mine still need to know the same number of letters and sounds and start those beginning reading skills.

\section{Younger Students Need More Support}

Several comments were made by teachers that described the youngest students as less developed, with increased challenges related to not being able to tie their shoes and separation difficulties as they tried to adjust to kindergarten. According to Audrey, who taught the youngest group of students at her school, "There is still a lot of crying. It took them longer to catch on, to get used to being away from Mom, being away from Dad or whatever. Didn't have the shoe-tier, couldn't color, couldn't hold or grasp a pencil." Jane S. posited that there was a certain type of teacher who would be successful with the youngest group of students and said the most successful teacher would be "ones you know who probably has a super kind, sympathetic heart to work with the little babies." However, Joan said that working with young students could also be very rewarding. She said, "I feel like I get to experience a little bit more reward with these babies that just have never thought that they could or someone's always done it for them. And then you see them getting that realization of, 'I can do this.' So that's exciting for me."

However, other teachers did not want the challenges of teaching the youngest students in the grade. Audrey commented

I think I would feel so overwhelmed and stressed everyday that "how in the world am I going to get them where they need to be?" Yes, they're growing and they're showing so much growth but just the fact that it takes so long and they need so much more. I think that I would be very, very overwhelmed.

The differences between the oldest and youngest students were not only observed in the classrooms. The teachers at both schools described the way the children played on the playground in very different ways. The oldest group of children played games with rules that had to be followed, while the youngest children played on the playground equipment. The three groups rarely mixed at recess and chose to play only with their same-aged peers. Teachers at both schools commented that behavior on the playground was better than it had been in previous years. It was unclear if the teachers had ever observed kindergarten students playing at recess through a relative age perspective.

\section{Discussion}

The teachers in this study spoke several times about younger students needing more time, practice and instruction than older students. In fact, many comments were made describing this group of students as "babies" and that they would not want to teach an entire class of the youngest students. These reactions show that teachers may be contributing to relative age effects and the hierarchy of leadership in a traditional, mixed-age classroom. By assigning older students leadership and caretaker roles over younger students, they are inadvertently telling students where they rank in ability and maturity when compared to their peers.

Older students are given leadership roles by teachers when they are asked to help students not only with academic skills but also with self-care skills such as putting on jackets and tying their shoes. By relegating 
the youngest students to roles in which they are constantly compared to older and more cognitively developed children, teachers are unknowingly creating barriers to achievement for these children.

Teachers in this study sometimes referred to the youngest children in their classes as "babies". Though the term was used in an affectionate manner, there was an understanding that these students stood out among the other students as being younger and less mature. There is also the risk of teachers having lower expectations for these children because they are not up to the same level of maturity as other children in the class.

When the entire class is made up of the youngest students in the grade, the teacher takes a more active role in supporting students and meeting them at their level. The teachers in this study took more time at the beginning of the year to work on executive functioning skills and adjustment to kindergarten. Students were not relegated to the lowest level of class hierarchy based solely on their age in comparison with another student in class.

Grouping by birthday helped the oldest groups of students, as well. The older students could move on to academic learning in less time at the beginning of the year because they did not need to spend as much time on executive functioning. Their own emotional development was guided by a teacher who had less of a range of age and development levels so that each child could grow at their own pace. Teachers of both groups were able to more effectively teach their students because the range of social and emotional skills in the classes were smaller and required less differentiation.

This study showed some promise in the practice of separating kindergarten students by birthday. However, teacher skill set and knowledge of relative age effects will make a difference in the success of this practice. The teachers of the youngest students must be able to support students in their adjustment to kindergarten and to meet them on their own level instead of comparing them to older children. But for teachers who prefer for their youngest students to learn from older children in the class instead of from instructional practices, the practice may be a negative experience for the teacher and the children. Teachers who are not ready or able to support the youngest children may have negative relationships with more of their students, which research has shown leads to less academic achievement.

\section{Implications for Practice}

Teacher perceptions of students is an important aspect of schooling. Children need to feel that they can trust their teacher and that their teacher likes them before they will be able to reach their academic potential. When teachers view the youngest students in class from a deficit-centered perspective, they may be allowing those students to fall behind their older peers. Several comments were made in the interviews about not wanting to be assigned an entire group of younger kindergarteners or having to be mentally prepared for the challenge. However, what happens to these children when they are in mixed age classrooms? It may be easier for teachers to accept that some of their students are not successful in reading and math by the end of the year as long as most of their students were on grade level. If all teachers of a particular school accept that the youngest students will also be the lowest achievers and worst behaved students, then those children will not receive the support they need to develop better academic and socioemotional skills. When combined with all the youngest students in the other classrooms, they represent a large number of students who are leaving kindergarten with fewer academic and socio-emotional skills. If their kindergarten teachers simply accept that the youngest students in their classes cannot and will not achieve at the same levels as their older peers, then they will not attempt to get them caught up. Thus, we are seeing the hockey effect in a school setting. If the topic were sports and the child's ability to play or not play hockey, there may not be any adverse consequences. However, all students need the opportunity to achieve in school. When teachers perceive students as having low ability, they may set lower expectations for those students to meet.

Grouping kindergarteners by birthday may eliminate some of these relative age effects because teachers are more willing to work on an entire class of young kindergarteners. Just as other risk factors that are out of a child's control, relative age in comparison with their classmates inadvertently puts the youngest students at risk because of the teacher's perceptions about these students and their abilities. 


\section{REFERENCES}

Alexander, K.L., \& Entwisle, D.R. (1988). Achievement in the first two years of school: Patterns and processes. Monographs of the Society for Research in Child Development, 53(2), 1-132.

Abry, T., Latham, S., Bassok, D., \& LoCasale-Crouch, J. (2015). Preschool and kindergarten teachers' beliefs about early school competencies: Misalignment matters for kindergarten adjustment. Early Childhood Research Quarterly, 31(2).

Barnsley, R.H., \& Thompson, A.H. (1988). Birthdate and success in minor hockey: The key to the NHL. Canadian Journal of Behavioral Science, 20(2), 167-176.

Datar, A. (2006). Does delaying kindergarten entrance give children a head start? Economics of Education Review, 25(1), 43-62.

Elder, T.E. (2010). The importance of relative standards in ADHD diagnoses: Evidence based on exact birth dates. Journal of Health Economics, 29, 641-656.

Graziano, P.A., Garb, L.R., Ros, R., Hart, K., \& Garcia, A. (2016). Executive functioning and school readiness among preschoolers with externalizing problems: The moderating role of the studentteacher relationship. Early Education and Development, 27(5), 573-589.

Graziano, P.A., Reavis, R.D., Keane, S.P., \& Calkins, S.D. (2007). The role of emotion regulation in children's early academic success. Journal of School Psychology, 45, 3-19.

Helsen, W.F., Van Winckel, J., \& Williams, A.M. (2005). The relative age effect in youth soccer across Europe. Journal of Sports Sciences, 23, 629-636.

Ladd, G.W., Herald, S.L., \& Kochel, K.P. (2006). School readiness: Are there social prerequisites? Early Education and Development, 17(1), 115-150.

Lin, H., Freeman, L.S., \& Chu, K. (2009). The impact of kindergarten enrollment age on academic performance through kindergarten to fifth grade. European Journal of Social Sciences, 10(1), 4554.

Morgan, P., Li, H., Farkas, G., Cook, M., Pun, W., \& Hillemeier, M. (2017). Executive functioning deficits increase kindergarten children's risk for reading and mathematics difficulties in first grade. Contemporary Educational Psychology, 50(2), 23-32.

Oshima, T.C., \& Domaleski, C.S. (2006). Academic performance gap between summer-birthday and fallbirthday children in grades K-8. Journal of Educational Research, 99(4), 212-217.

Pagani, L.S., \& Allard, A. (2011). Links between developmental change in kindergarten behaviors and later peer associations. Journal of Educational and Developmental Psychology, 1(1), 45-53.

Raver, C.C. (2002). Emotions matter: Making the case for the role of young children's emotional development for early school readiness. Social Policy Report, 16(3), 3-19.

Sasser, T., Bierman, K., \& Heinrichs, B. (2015). Executive functioning and school adjustment: The mediational role of pre-kindergarten learning-related behaviors. Early Childhood Research Quarterly, 30(1), 70-79.

Wake, M., Coghlan, D., \& Hesketh, K. (2000). Does height influence progression through primary grades? Archives of Disease in Childhood, 82, 297-301.

Yesil-Dagli, U. (2006). The effects of kindergarten entrance age on children's reading and mathematics achievement from kindergarten through third grade. Doctoral Dissertation, Florida State University. Retrieved from_http://etd.lib.fsu.edu/theses/available/etd-05012006113623/unrestricted/UYD_dissertation.pdf

Zulfiqar, N., LoCasale-Crouch, J., Sweeney, B.D., DeCoster, J., Rudasill, K., McGinnis, C., . . Miller, K. (2018). Transition practices and children's development during kindergarten: The role of close teacher-child relationships. In A. Mashburn, J. LoCasale-Crouch, \& K. Pears (Eds.), Kindergarten Transition and Readiness. Springer, Cham. 